\title{
New Perspective in Pain Treatment
}

\author{
Luigi F. Rodella*, Elisa Borsani and Rita Rezzani
}

Division of Human Anatomy, Department of Biomedical Sciences and Biotechnologies, University of Brescia, V.le Europa 11, 25123 Brescia, Italy

\begin{abstract}
Pain is a disabling condition with a remarkable clinical relevance. Nevertheless the neuronal basis of its transmission and modulation are not completely known. So, the neurochemical characterisation of the nociceptive pathway plays a pivotal role to develop new analgesic strategies. Several factors and chemicals are involved in the activation of the nociceptive pathway both in peripheral (PNS) and central (CNS) nervous system. Recently, a number of researches focus on the role of cannabinergic, purinergic, glutamatergic and nitroxidergic systems in pain transmission showing that new drugs interfering with these systems could be useful for pain treatment. In addition, other molecules, such antioxidants and aquaporins, which are not classified as chemical/neurochemical mediators, can be altered during pain processing and interfere with nociceptive trasmission. Moreover, there is an increased evidence that activated glia and nerve growth factor (NGF) could be involved in the induction and maintenance of pain. Finally, stem cell transplantation shows potential therapeutic effects in neuropathic pain conditions. In this paper the recent results about new molecules acting on cannabinergic, purinergic, glutamatergic and nitroxidergic systems, NGF and stem cell transplantation involvement in pain treatment, will be discussed.
\end{abstract}

Keywords: Pain transmission, therapeutic strategies.

\section{INTRODUCTION}

Pain is an unpleasant sensory and emotional experience which moves from perceptive modes and is affected by personal and individual interpretations according to past or present experiences. For these reasons, a stimulus can be intensely painful for some individuals but not for others.

Pain modulation occurs at many levels: from stimulation site to the pathways that convey the painful information to the cerebral cortex. Here, we can find systems able to modify the organism's emotional reactions to pain causing a variability of human pain perception.

From a temporal point of view, we can discriminate between acute and chronic pain; while from pathogenetic point of view, we should discriminate between nociceptive pain, neuropathic pain (peripheral or central) and mixed pain, i.e., a combination of nociceptive and neuropathic pain.

Of the different kinds of pain the most intriguing and complex appears to be neuropathic pain. Chronic neuropathic pain syndrome is a disabling condition which can be a much greater challenge for the clinician than acute pain. Its neural basis is poorly understood as it is only recently that the availability of animal models for these conditions permitted us to understand some of the physiopathological changes better during chronic pain [1,2]. The limitations of treatment and the inability to provide relief for many patients stimulated studies examining different approaches of treating neuropathic pain [3].

*Address correspondence to this author at the Division of Human Anatomy, Department of Biomedical Sciences and Biotechnologies, University of Brescia, V.le Europa 11, 25123 Brescia, Italy; Tel: +39-030-3717485; Fax: +39-030-3717486; E-mail: rodella@med.unibs.it
Several neuropathic pain situations may be related to a dysfunctional brain network and may involve compromised descending inhibitory control systems (central neuropathic pain). Furthermore, tissue damage may lead to abnormal changes in afferent endings and so-called ectopic or aberrant neural discharges. These changes seem to be important in the development of many types of peripheral neuropathic pain $[4,5]$. This is also considering that damage of peripheral tissues often causes inflammation releasing products from blood vessels or from other tissues including immune system cells. The most common condition is peripheral neuropathic pain due to nerve injury which produces sensory/motor deficits and other qualitative paradoxical sensations such as hyperalgesia/allodynia, for which currently there is no effective treatment [6]. This neuropathic pain state is often refractory to opioids or needs larger doses producing unacceptable side effects [7].

\section{NEUROCHEMISTRY OF PAIN}

Several factors and chemicals are involved in activating the nociceptive afferent by noxious stimulation of the peripheral endings within the receptive field such as opioids, serotonin, ATP (adenosine-5'-triphosphate), glutamate, substance $\mathrm{P}$, nitric oxide, inflammatory mediators, endocannabinoids [5,8-11]. Tissue damage produced by the noxious stimulus causes the release of chemical mediators from surrounding tissues (e.g. prostaglandins, bradykinins). These substances can activate the nerve endings and this then can excite the afferent and produce potential afferent activity. In addition, other molecules, which are not classified as chemical/neurochemical mediators such as aquaporins can be altered during pain processing [12]. Finally, there is increasing evidence that activated glia (microglia and astrocytes) [13-16] and nerve growth factor 
(NGF) $[17,18]$ are fundamental in inducing and maintaining pain.

This wide classification of pain needs differentiated therapies, including pharmacological treatment and sometimes more invasive treatment but which do not offer completely satisfactory results.

Several analgesic drugs are currently available and their use follows the useful and well-known WHO (World Health Organization) "ladder". NSAIDs (non-steroidal antiinflammatory drugs) are one of the first step of this ladder being the most commonly used, also through self prescription. The second step comprises weak opioids such as codeine and tramadol; they are used for medium to strong intensity pain. The third step counts on strong opioids including morphine, fentanyl, buprenorfine, methadon..etc.; they are suitable for strong to intolerable pain.

Pharmacological therapy is also based on using other drugs, so-called "adjuvants", which are different molecules that have an intrinsic analgesic effect and/or the possibility to strengthen the analgesic action of opioids. Tricyclic antidepressant and anti-epileptics are the most frequently used in treating neuropathic pain. In addition local anaesthetics, clonidin, benzodiazepines, neuroleptics, beta-blockers are also used.

To date new pharmacological approaches have been evaluated which modulate molecules and seem to be important in pain relief.

\section{Cannabinoid System Modulation}

Although pain perception is thought to be controlled mainly by neurotransmitter systems that operate within the central nervous system (CNS), anti-nociceptive mechanisms also occur in peripheral tissues. The potent analgesic effects of cannabis-like drugs and the presence of cannabinoid receptors in pain-processing areas of the brain and spinal cord indicate that endogenous cannabinoids such as anandamide may modulate pain transmission.

Over the last twenty years, and especially after the discovery of the cannabinoid CB1 receptor and anandamide, intense research has yielded numerous series of drugs that interact with most of the main elements of the endogenous cannabinoid system. Mammalian tissues contain at least two types of cannabinoid receptors, cannabinoid $\mathrm{CB}_{1}$ receptor and cannabinoid $\mathrm{CB}_{2}$ receptor, both coupled to $\mathrm{G}$ proteins [19]. Cannabinoid $\mathrm{CB}_{1}$ receptors are expressed mainly by neurones of the CNS and PNS whereas cannabinoid $\mathrm{CB}_{2}$ receptors occur centrally and peripherally in some nonneuronal tissues, particularly in immune cells and are involved both in acute and in chronic pain [20]. Cannabinoid receptor agonists may mimic the signalling processes mediated by anandamide and 2-AG, mainly in pathological situations where a boost in cannabinoid receptor stimulation might be needed such as WIN55,212-2 ((R)-(+)-[2,3Dihydro-5-methyl-3-(4-morpholinylmethyl)pyrrolo[1,2,3-de)1,4-benzoxazin-6-yl]-1-napthalenylmethanone) [21]. Cannabinoid receptor antagonism can be selected in conditions with enhanced endocannabinoid signalling, using drugs such as AM251 (1-(2,4-dichlorophenyl)-5-(4-iodophenyl)-4methyl- $N$-(1-piperidyl)pyrazole-3-carboxamide) [22]. Transport inhibition and degradation inhibition are more sophisticated approaches, both oriented towards magnifying the tonic actions of endocannabinoids using drugs such as AM404 ((5Z,8Z,11Z,14Z)- $\quad N$-(4-hydroxyphenyl)icosa$5,8,11,14$-tetraenamide) $[23,24]$. A rational use of these strategies needs to identify and evaluate the functional status of endocannabinoid signalling in reference disorders. So, a deficit of anandamide signalling during stress might be counteracted by blocking anandamide degradation [25].

\section{Glutamate Modulation}

Glutamate is the transmitter of most fast excitatory synapses in the mammalian CNS with two kinds of receptors: ionotropic and metabotropic receptors which are expressed in areas of the brain, spinal cord and periphery involved in pain sensation and transmission [26]. Recently, the role of metabotropic glutamate receptors (mGluRs) has been focused [27]; they are preferentially involved in transmitting noxious sensory information in the thalamus and may be involved in enhancing long-term responses to noxious stimuli in the spinal cord. Selective antagonists for the mGluRs subtypes that interact with transmission of noxious sensory information could be useful in to treat acute and chronic pain.

Activation of mGlu receptors along the pain neuraxis can cause either pro-nociceptive or anti-nociceptive behaviour depending on the subtype of mGluR and its location. Present data most strongly support the idea that mGlu1 antagonists, such as LY367385 ((+)-2-Methyl-4-carboxyphenylglycine) [28], might act like broad-spectrum analgesics like. However, also mGluR5 antagonists, such as MPEP (2methyl-6-(phenylethynyl)-pyridine) [29] seem to be involved in neuropathic and/or visceral pain relief [30,31]. The recent literature on the anti-nociceptive action of ionotropic glutamate receptor antagonists, such as D-AP5 (D-(-)-2Amino-5-phosphonopentanoic acid) [32], has been reviewed with special emphasis on their clinical potential. Presently the glutamatergic pathways descending from the brain stem into the spinal cord may generate analgesia. However, physiologically more important is the fact that glutamate and aspartate are apparently the main neurotransmitters along the ascending nociceptive pathways in the spinal cord.

\section{ATP Modulation}

ATP is an intercellular messenger molecule that interacts with purinoceptors on a broad range of cell types [33,34]. Purinoceptors are classified into G-protein coupled receptors P2Y and ATP-gated cation channels so-called P2X receptors. These are localized in the CNS and PNS and they play an important role in excitatory nociceptive processing $[35,36]$. ATP is released from neuronal and non-neuronal cells and can reach high concentrations flowing out from cells into the extra-cellular space, exocytotically, via transmembrane transport, or as a result of cell damage. It plays an important role in the initiation of pain and in central sensitisation after different kinds of acute in nervous system injury [37,38]. Antagonists of this receptors, such as PPADS (pyridoxal-phosphate-6-azophenyl-2',4'-disulfonate), seem to have had promising results [39].

\section{Nitric Oxide Modulation}

It has been demonstrated that nitric oxide $(\mathrm{NO})$ is involved in pain transmission. NO is a small gaseous 
molecules that could be synthesized de novo by neuronal tissue and diffused through the plasma membrane [40]. NO is produced within the nervous cells mainly by two isoforms of nitroxidergic synthase (NOS), a constitutive (neuronal) isoform (nNOS) and an inducible isoform (iNOS), which participate in pain transmission in different ways [39,41,42]. The third form is endothelial NOS (eNOS). The physiological relevance of $\mathrm{NO}$ is determined by its pleiotropic effects and its involvement in various diseases, opening the possibility of pharmacological treatment directed towards NO metabolic pathways. Therapies based on increasing NO effects or donating exogenous NO have been extensively investigated and drugs acting as NO-donors are well known and used clinically, whereas therapies based on reducing $\mathrm{NO}$ effects have become known only recently. Therefore, several research groups have focused on developing compounds that reduce NO synthesis inhibiting NOS. Despite the intensive efforts of inventing NOS inhibitors, today no clinically useful compound is yet available, but several inhibitors have been developed or researched such as L-NIO (L-N(5)-(1-iminoethyl)-ornithine) a selective eNOS inhibitor [43] and TRIM (1-[2(trifluoromethyl)phenyl] imidazolo) a selective iNOS/nNOS inhibitor $[44,45]$.

\section{Aquaporins Modulation}

Various studies provided indirect evidence of osmosis contributing to altered pain perception [46-48]. Forty years ago, Hitchcock (1969) [49] reported that intrathecal injections of cold saline into patients with intractable pain led to immediate relief. It has been proposed that the differences in water flux underlie the preferential conduction block of C-fibers. Although anatomical differences between A- and C-fibers were offered as a possible explanation, Oshio et al. (2006) [46] suggested that the differential expression of aquaporins (AQPs) in C-fibers may account for these results and provided a molecular basis for osmosis in pain pathways. AQPs are small hydrophobic membrane proteins that facilitate bi-directional water transport across the plasma membrane in a number of tissues, including the nervous system [50,51]. Recently, a relationship between AQPs expression and pain transmission has been observed $[12,52]$. To date no drugs are available for these promising molecules.

\section{NGF}

NGF (nerve growth factor) has been linked to hyperalgesic behaviour. A single systemic injection of NGF can lead to deep and long-lasting heat and mechanical hyperalgesia in neonatal and adult rats [53,54]. Previous studies reported that NGF produces this hyperalgesia through peripheral and central mechanisms [55,56].

However, there is evidence that NGF reverses some effects of axotomy and alleviates thermal hyperalgesia [57]. So, NGF represent a new potential target for pain modulation $[17,18]$.

\section{Stem Cells}

Stem cells are an innovative and interesting therapeutic approach for tissue repair, particularly for nervous tissues $[58,59]$. However, the effects of stem cell use in peripheral neuropathic pain has not been well documented. In particular, news about their effects on the parameters cited above and on the precise location and activity sites of administered stem cells are not available.

Studies have already been attempted to modulate CNSor PNS-lesion derived neuropathic pain by using centrally administered stem cells of different origin with general unsatisfactory results, but also with some comfortable data [60]. On the other hand, treatment with stem cells starting from the periphery (e.g. intravenous) could be a revolutionary approach [59].

\section{CONCLUSIONS}

New perspectives in pain treatment opened up new possibilities of new targets and new kind of tools to relieve pain. In this paper we reported both the involvement of several molecules acting as antinociceptive drugs and new approaches using stem cell therapy. Further neurobiological and pharmacological researches could be useful to better characterize them representing an important source of other innovative strategies.

\section{ACKNOWLEDGEMENTS}

We thank Dr. R. Coates for the English revision of the manuscript.

\section{ABBREVIATIONS}

\begin{tabular}{|c|c|}
\hline AM251 & $\begin{aligned}= & (1-(2,4-\text { dichlorophenyl)-5-(4-iodophenyl)- } \\
& \text { 4-methyl } N \text {-(1-piperidyl)pyrazole-3- } \\
& \text { carboxamide })\end{aligned}$ \\
\hline AM404 & $\begin{aligned}= & ((5 Z, 8 Z, 11 Z, 14 Z)-N-(4- \\
& \text { hydroxyphenyl)icosa-5,8,11,14- } \\
& \text { tetraenamide })\end{aligned}$ \\
\hline AQPs & $=$ Aquaporins \\
\hline ATO & $=$ Adenosine-5'-triphosphate \\
\hline CNS & $=$ Central Nervous System \\
\hline D-AP5 & $\begin{aligned}= & \mathrm{D}-(-)-2-\text { Amino-5-phosphonopentanoic } \\
& \text { acid }\end{aligned}$ \\
\hline eNOS & $=$ Endothelial Nitric Oxide Synthase \\
\hline iNOS & $=$ Inducible Nitric Oxide Synthase \\
\hline mGluRs & $=$ Metabotropic Glutamate Receptors \\
\hline L-NIO & $=\mathrm{L}-\mathrm{N}(5)-(1$-iminoethyl)-ornithine $)$ \\
\hline MPEP & $=2$-methyl-6-(phenylethynyl)-pyridine $)$ \\
\hline NGF & $=$ Nerve Growth Factor \\
\hline nNOS & $=$ Neuronal Nitric Oxide Synthase \\
\hline PPADS & $\begin{aligned}= & \text { Pyridoxal-phosphate-6-azophenyl-2',4'- } \\
& \text { disulfonate) }\end{aligned}$ \\
\hline TRIM & $=1-[2-($ trifluoromethyl)phenyl $]$ imidazolo \\
\hline WHO & $=$ World Health Organization \\
\hline WIN55,212-2 & $\begin{aligned}= & ((\mathrm{R})-(+)-[2,3-\text { Dihydro-5-methyl-3- }(4 \\
& \text { morpholinylmethyl)pyrrolo[1,2,3-de)-1,4- } \\
& \text { benzoxazin-6-yl]-1- } \\
& \text { napthalenylmethanone })\end{aligned}$ \\
\hline
\end{tabular}

\section{REFERENCES}

[1] Bennett, G.J.; Xie, Y.K. A peripheral mononeuropathy in rat that produces disorders of pain sensation like those seen in man. Pain, 1988, 33, 87-107. 
[2] Kim, S.H.; Chung, J.M. An experimental model for peripheral neuropathy produced by segmental spinal nerve ligation in the rat. Pain, 1992, 50, 355-63.

[3] Dworkin, R.H. An overview of neuropathic pain: syndromes, symptoms, signs, and several mechanisms. Clin. J. Pain, 2002, 18, 343-9.

[4] Eliav, E.; Gracely, R.H.; Nahlieli, O.; Benoliel, R. Quantitative sensory testing in trigeminal nerve damage assessment. J. Orofac. Pain, 2004, 18, 339-44.

[5] Robinson, P.P.; Boissonade, F.M.; Loescher, A.R.; Smith, K.G.; Yates, J.M.; Elcock, C.; Bird, E.V.; Davies, S.L.; Smith, P.L.; Vora, A.R. Peripheral mechanisms for the initiation of pain following trigeminal nerve injury. J. Orofac. Pain, 2004, 18, 28792.

[6] Saarto, T.; Wiffen, P.J. Antidepressants for neuropathic pain. Cochrane Database Syst. Rev., 2005, 3, CD005454.

[7] Przewlocki, R.; Przewlocka, B. Opioids in neuropathic pain. Curr. Pharm. Des., 2005, 11, 3013-25.

[8] Burnstock G. Purinergic receptors and pain. Curr. Pharm. Des., 2009, 15, 1717-35.

[9] Goudet, C.; Magnaghi, V.; Landry, M.; Nagy, F.; Gereau, R.W. $4^{\text {th }}$; Pin, J.P. Metabotropic receptors for glutamate and GABA in pain. Brain Res. Rev., 2009, 60, 43-56.

[10] Okuse, K. Pain signalling pathways: from cytokines to ion channels. Int. J. Biochem. Cell. Biol., 2007, 39, 490-96.

[11] Welch, S.P. Interaction of the cannabinoid and opioid systems in the modulation of nociception. Int. Rev. Psychiatry, 2009, 21, 143151 .

[12] Borsani, E.; Bernardi, S.; Albertini, R.; Rezzani, R.; Rodella, L.F. Alterations of AQP2 expression in trigeminal ganglia in a murine inflammation model. Neurosci. Lett., 2009, 449, 183-8.

[13] Inoue, K. The function of microglia through purinergic receptors: neuropathic pain and cytokine release. Pharmacol. Ther., 2006, 109, 210-26.

[14] McMahon, S.B.; Cafferty, W.B.; Marchand, F. Immune and glial cell factors as pain mediators and modulators. Exp. Neurol., 2005, 192, 444-62.

[15] Tsuda, M.; Shigemoto-Mogami, Y.; Koizumi, S.; Mizokoshi, A.; Kohsaka, S.; Salter, M.W.; Inoue, K. P2X4 receptors induced in spinal microglia gate tactile allodynia after nerve injury. Nature, 2003, 424, 778-83.

[16] Watkins, L.R.; Milligan, E.D.; Maier, S.F. Spinal cord glia: new players in pain. Pain, 2001, 93, 201-5.

[17] Jing, Y.Y.; Wang, J.Y.; Li, X.L.; Wang, Z.H.; Pei, L.; Pan, M.M.; Dong, X.P.; Fan, G.X.; Yuan, Y.K. Nerve growth factor of red nucleus involvement in pain induced by spared nerve injury of the rat sciatic nerve. Neurochem. Res., 2009, 34, 1612-8.

[18] Watson, J.J.; Allen, S.J.; Dawbarn, D. Targeting nerve growth factor in pain: what is the therapeutic potential? BioDrugs., 2008, 22, 349-59.

[19] Rice, A.S.C. Cannabinoids and pain. Curr. Opin. Investig. Drugs, 2001, 2, 399- 414.

[20] Mackie, K. Distribution of cannabinoid receptors in the central and peripheral nervous system. Handb. Exp. Pharmacol., 2005, 299325 .

[21] Leichsenring, A.; Andriske, M.; Bäcker, I.; Stichel, C.C.; Lübbert, H. Analgesic and antiinflammatory effects of cannabinoid receptor agonists in a rat model of neuropathic pain. Naunyn. Schmiedebergs Arch. Pharmacol., 2009, 379, 627-36.

[22] Akerman, S.; Kaube, H.; Goadsby, P.J. Anandamide is able to inhibit trigeminal neurons using an in vivo model of trigeminovascular-mediated nociception. J. Pharmacol. Exp. Ther., 2004, 309, 56-63.

[23] Borsani, E.; Labanca, M.; Bianchi, R.; Rodella, L.F. AM404 decreases Fos-immunoreactivity in the spinal cord in a model of inflammatory pain. Brain Res., 2007, 1152, 87-94.

[24] Rodella, L.F.; Borsani, E.; Rezzani, R.; Ricci, F.; Buffoli, B.; Bianchi, R. AM404, an inhibitor of anandamide reuptake decreases Fos-immunoreactivity in the spinal cord of neuropathic rats after non-noxious stimulation. Eur. J. Pharmacol., 2005, 508, 139-46.

[25] Kathuria, S.; Gaetani, S.; Fegley, D.; Valiño, F.; Duranti, A.; Tontini, A.; Mor, M.; Tarzia, G.; La Rana, G.; Malignano, A.; Giustino, A.; Tattoli, M.; Palmery, M.; Cuomo, V.; Pomelli, D. Modulation of anxiety through blockade of anandamide hydrolysis. Nat. Med., 2003, 9, 76-81.
[26] Dickenson, A.H.; Chapman, V.; Green, G.M. The pharmacology of excitatory and inhibitory amino acid-mediated events in the transmission and modulation of pain in the spinal cord. Gen. Pharmacol., 1997, 28, 633-8.

[27] Olive, M.F. Metabotropic glutamate receptor ligands as potential therapeutics for addiction. Curr. Drug Abuse Rev., 2009, 2, 83-989.

[28] Clark, B.P.; Baker, S.R.; Goldsworthy, J.; Harris, J.R.; Kingston A.E. (+)-2-Methyl-4-carboxyphenylglycine (LY367385) selectively antagonises metabotropic glutamate mGluR1 receptors. Bioorg. Med. Chem. Lett., 1997, 7, 2777-80.

[29] Gasparini, F.; Lingenhöhl, K.; Stoehr, N.; Flor, P.J.; Heinrich, M.; Vranesic, I.; Biollaz, M.; Allgeier, H.; Heckendorn, R.; Urwyler, S.; Varney, M.A.; Johnson, E.C.; Hess, S.D.; Rao, S.P.; Sacaan, A.I.; Santori, E.M.; Veliçelebi, G.; Kuhn, R. 2-Methyl-6(phenylethynyl)-pyridine (MPEP), a potent, selective and systemically active mGlu5 receptor antagonist. Neuropharmacology, 1999, 38, 1493-1503.

[30] Bianchi, R.; Rezzani, R.; Borsani, E.; Rodella, L. mGlu5 receptor antagonist decreases Fos expression in spinal neurons after noxious visceral stimulation. Brain Res., 2003, 960, 263-6.

[31] Osikowicz, M.; Skup, M.; Mika, J.; Makuch, W.; CzarkowskaBauch, J.; Przewlocka, B. Glial inhibitors influence the mRNA and protein levels of $\mathrm{mGlu} 2 / 3,5$ and 7 receptors and potentiate the analgesic effects of their ligands in a mouse model of neuropathic pain. Pain, 2009, 147, 175-86.

[32] Wong, C.S.; Wu, G.J.; Chen, W.F.; Jean, Y.H.; Hung, C.H.; Lin, C.S.; Huang, S.Y.; Wen, Z.H. N-Methyl-D-aspartate receptor antagonist d-AP5 prevents pertussis toxin-induced alterations in rat spinal cords by inhibiting increase in concentrations of spinal CSF excitatory amino acids and downregulation of glutamate transporters. Brain Res. Bull., 2009, 80, 69-74.

[33] Burnstock, G. Introduction: P2 receptors. Curr. Top Med. Chem., 2004, 4, 793-803.

[34] Kennedy, C. P2X receptors: targets for novel analgesics? Neuroscientist, 2005, 11, 345-56.

[35] Burnstock, G. Purinergic P2 receptors as targets for novel analgesics. Pharmacol. Ther., 2006, 110, 433-54.

[36] Liu, X.Y.; Salter, M.V. Purines and pain mechanisms: recent developments. Curr. Opin. Investig. Drugs, 2005, 6, 65-75.

[37] Agteresch, H.J.; Dagnelie, P.C.; van der Berg, J.W.; Wilson, J.H. Adenosine triphosphate: established and potential clinical applications. Drugs, 1999, 58, 211-32.

[38] Schwiebert, E.M. Extracellular ATP-mediated propagation of $\mathrm{Ca}(2+)$ waves. Focus on "mechanical strain-induced $\mathrm{Ca}(2+)$ waves are propagated via ATP release and purinergic receptor activation". Am. J. Physiol. Cell. Physiol., 2000, 279, C281-3.

[39] Martucci, C.; Trovato, A.E.; Costa, B.; Borsani, E.; Franchi, S.; Magnaghi, V.; Panerai, A.E.; Rodella, L.F.; Valsecchi, A.E.; Sacerdote, P.; Colleoni, M. The purinergic antagonist PPADS reduces pain related behaviours and interleukin-1 beta, interleukin 6 , iNOS and nNOS overproduction in central and peripheral nervous system after peripheral neuropathy in mice. Pain, 2008, $137,81-95$.

[40] Haley, J.E. Gases as neurotransmitters. Essays Biochem., 1998, 33, 79-91.

[41] Jenkins, D.C.; Charles, I.G.; Baylis, S.A.; Lelchuk, R.; Radomski, M.W.; Moncada, S. Human colon cancer cell lines show a diverse pattern of nitric oxide synthase gene expression and nitric oxide generation. Br. J. Cancer, 1994, 70, 847-9.

[42] Watkins, L.R. ; Maier, S.F. Glia: a novel drug discovery target for clinical pain. Nat. Rev. Drug Discov., 2003, 2, 973-85.

[43] Rees, D.D.; Palmer, R.M.; Schulz, R.; Hodson, H.F.; Moncada, S. Characterization of three inhibitors of endothelial nitric oxide synthase in vitro and in vivo. Br. J. Pharmacol., 1990, 101, 746-52.

[44] Handy, R.L.; Fallace, P.; Gaffen, Z.A.; Whitehead, K.J.; Moore, P.K. The antinociceptive effect of 1-(2-trifluoromethylphenyl) imidazole (TRIM), a potent inhibitor of neuronal nitric oxide synthase in vitro, in the mouse. Br. J. Pharmacol., 1995, 116, 2349-50.

[45] Handy, R.L.; Harb, H.L.; Fallace, P.; Gaffen, Z.; Whitehead, K.J.; Moore, P.K. Inhibition of nitric oxide synthase by $1-(2$ trifluoromethylphenyl) imidazole (TRIM) in vitro: antinociceptive and cardiovascular effects. Br. J. Pharmacol., 1996, 119, 423-31.

[46] Oshio, K.; Watanabe, H.; Yan, D.; Verkman, A.S.; Manley, G.T. Impaired pain sensation in mice lacking Aquaporin-1 water channels. Biochem. Biophys. Res. Commun., 2006, 341, 1022-8. 
[47] Shields, S.D.; Mazario, J.; Skinner, K.; Basbaum, A.I. Anatomical and functional analysis of aquaporin 1 , a water channel in primary afferent neurons. Pain, 2007, 131, 8-20.

[48] Solenov, E.I.; Vetrivel, L.; Oshio, K.; Manley, G.T.; Verkman, A.S. Optical measurement of swelling and water transport in spinal cord slices from aquaporin null mice. J. Neurosci. Methods, 2002, $113,85-90$.

[49] Hitchcock, E. Osmolytic neurolysis for intractable facial pain. Lancet, 1969, 1, 434-6.

[50] Manley, G.T.; Fujimura, M.; Ma, T.; Noshita, N.; Filiz, F.; Bollen, A.W.; Chan, P.; Verkman, A.S. Aquaporin-4 deletion in mice reduces brain edema after acute water intoxication and ischemic stroke. Nat. Med., 2000, 6, 159-63.

[51] Manley, G.T.; Binder, D.K.; Papadopoulos, M.C.; Verkman, A.S. New insights into water transport and edema in the central nervous system from phenotype analysis of aquaporin-4 null mice. Neuroscience, 2004, 129, 983-91.

[52] Buffoli, B.; Borsani, E.; Rezzani, R.; Rodella, L.F. Chronic constriction injury induces aquaporin-2 expression in the dorsal root ganglia of rats. J. Anat., 2009, 215, 498-505.

[53] Andreev, N.Yu.; Dimitrieva, N.; Koltzenburg, M.; McMahon, S.B. Peripheral administration of nerve growth factor in the adult rat produces a thermal hyperalgesia that requires the presence of sympathetic post-ganglionic neurones. Pain, 1995, 63, 109-15.
[54] Lewin, G.R.; Ritter, A.M.; Mendell, L.M. Nerve growth factorinduced hyperalgesia in the neonatal and adult rat. J. Neurosci., 1993, 13, 2136-48.

[55] Anand, P. Neurotrophic factors and their receptors in human sensory neuropathies. Prog. Brain Res., 2004, 146, 477-92.

[56] Lewin, G.R.; Mendell, L.M. Nerve growth factor and nociception. Trends Neurosci., 1993, 16, 353-9.

[57] Ren, K.; Thomas, D.A.; Dubner, R. Nerve growth factor alleviates a painful peripheral neuropathy in rats. Brain Res., 1995, 699, 28692.

[58] Goldman, S. Stem and progenitor cell-based therapy of the human central nervous system. Nat. Biotechnol., 2005, 23, 862-871.

[59] Klass, M.; Gavrikov, V.; Drury, D.; Stewart, B.; Hunter, S.; Denson, D.D.; Hord, A.; Csete, M. Intravenous mononuclear marrow cells reverse neuropathic pain from experimental mononeuropathy. Anesth. Analg., 2007, 104, 944-8.

[60] Siniscalco, D.; Giordano, C.; Galderisi, U.; Luongo, L.; Alessio, N.; Di Bernardo, G.; de Novellis, V.; Rossi, F.; Maione, S. Intrabrain microinjection of human mesenchymal stem cells decreases allodynia in neuropathic mice. Cell. Mol. Life Sci., 2010, 67, 65569.

(C) Rodella et al.; Licensee Bentham Open.

This is an open access article licensed under the terms of the Creative Commons Attribution Non-Commercial License (http://creativecommons.org/licenses/by-nc/3.0/) which permits unrestricted, non-commercial use, distribution and reproduction in any medium, provided the work is properly cited. 